\title{
LABORATORY FINDINGS IN PSORIATIC ARTHRITIS
}

\author{
L. PUNZI, M. PODSWIADEK, F. OLIVIERO, A. LONIGRO, V. MODESTI, \\ R. RAMONDA, S. TODESCO \\ Rheumatology Unit, Department of Clinical and Experimental Medicine, University of Padova, Italy
}

\begin{abstract}
SUMMARY
Psoriatic arthritis (PSA) has been classically defined as an inflammatory arthritis associated with psoriasis. However, in comparison with other relevant inflammatory arthropathies, in which a definite diagnosis is frequently possible only by means of laboratory investigations, in PsA true laboratory diagnostic markers are lacking. Some markers are utilised more to differentiate other diseases than to characterise PsA. For example in polyarticular PsA, which may be in some cases indistinguishable from $R A$, the rheumatoid factor $(R F)$ or the more specific and recently introduced antibodies to cyclic citrullinated peptides (anti-CCP), may be useful to better identify RA. However, RF was found in $5 \%$ to $13 \%$ of patients with PsA, and anti-CCP may be observed in almost similar percentage. The determination of ESR and/or CRP is frequently disappointing in PSA, since they are both elevated in only half of the patients with PsA. However, ESR and/or CRP are included in the most utilised response criteria for RA, such as ACR and DAS, and, in addition are also considered reliable in the assessment of PSA. Furthermore, elevated levels of ESR have been proposed as one of the best predictors of damage progression and, in addition, a low ESR seems protective, while an ESR $>15 \mathrm{~mm} / \mathrm{h}$ is one of the factors associated with an increased mortality in PSA. The synovial fluid (SF) effusion is much higher in PSA, in comparison with other arthropathies. When available, SF analysis may offer additive information useful for the diagnosis, such as the increased number of leukocytes, which underlines the inflammatory nature of the effusion even in a patient with normal serum levels of acute phase response. We found that elevated IL-1 levels in SF of patients with early disease (<6 months), may be predictive of an evolution in polyarticular form at follow-up. This observation is in keeping with the crucial role that inflammatory cytokines play in PsA, probably related to a genetic predisposition. The recent introduction in PSA of anti-TNF- $\alpha$ agents and the demonstration of their efficacy in the management of many clinical disease expressions including peripheral arthropathy, axial involvement, enthesopathy and skin manifestations, have stimulated the research also in the field of the possible laboratory markers.
\end{abstract}

Key words: Psoriatic arthritis, laboratory investigations arthritis

\section{INTRODUCTION}

Psoriatic arthritis (PsA) has been classically defined as an inflammatory arthritis associated with psoriasis (1). However, this definition reflects only in part the large spectrum of musculoskeletal disorders found in patients with psoriasis (2). Thus, due to the heterogeneity of its expression, PsA may be overdiagnosised or underdiagnosised (3). Patients with arthropathy or enthesopathy of various types, psoriasis may be overdiagnosed as PsA in presence of cutaneous.

\footnotetext{
Corresponding author:

Leonardo Punzi MD, PhD

Chief, Rheumatology Unit

University of Padova

Via Giustiniani 2 - 35128 Padova, Italy

E-mail: punzireu@unipd.it
}

Conversely, in some others the diagnosis may be missed, especially in the absence of psoriasis, when important clinical and radiological hallmarks of PsA are misinterpreted. Another reason for missed or late diagnosis in PsA is the frequent normality of acute phase response indices, in particular erythrocyte sedimentation rate (ESR) and $\mathrm{C}$ reactive protein (CRP). This latter evidence is probably the main cause for considering PsA as the inflammatory arthropathy in which laboratory investigations are less useful.

However, in a more accurate approach to this disease, laboratory investigations may offer important additional tools to better interpret the various and heterogeneous spectrum of the disease expression of PsA. Laboratory investigations may be utilised to obtain information in the fields of diagnosis, disease activity, prognosis and evaluation of the effects of therapy. 


\section{DIAGNOSIS}

In comparison with other relevant inflammatory arthropathies, such as gout, infectious arthritis, rheumatoid arthritis (RA), and reactive arthritis, all diseases in which a definite diagnosis is frequently possible only by means of laboratory investigations, in PsA true laboratory diagnostic markers are lacking. In fact, some markers are used more to differentiate other diseases than to characterise PsA. For example in polyarticular PsA, which may be in some cases indistinguishable from RA, some laboratory markers, such as rheumatoid factor (RF) or the more specific and recently introduced antibodies to cyclic citrullinated peptides (antiCCP), may be useful to better identify RA. However, RF was found in 5\% to $13 \%$ of patients with PsA $(4,5)$ and anti-CCP may be found in almost similar percentage $(6,7)$. In a recent paper by Helliwell, reporting the results of the CASPAR study, anti-CCPs were detected in 26/588 patients with PsA (\%), 15/388 (7\%) with polyarticular variety and 11/200 (10\%) with non-polyarticular PsA (6). These data, showing that the occurrence of antiCCP was not limited to the polyarthritis, confirmed those reported by another recent study by Bogliolo et al (7). Anti-CCPs were detected in $16 / 102$ patients $(15.7 \%)$, which were mostly $(68 \%)$ affected with symmetric polyarthritis, and in $2 / 20(10 \%)$ with either mono-oligoarthritis. In this population, 19/102 patients have RF and anti-CCPs were present in 11 of them. Thus in PsA, the presence of anti-CCP is not restricted to those with clinical pictures resembling RA and so they seem unreliable as a marker of RA. However, as in RA, their presence is associated with an increased number of erosions, probably reflecting a more severe outcome (7).

As mentioned above, the determination of ESR and/or CRP is frequently disappointing in PsA, since they are both elevated in only half of the patients with PsA $(4,5,8)$. In a multicenter study examining the characteristics of 1306 Italian patients with PsA, abnormal levels of ESR and CRP respectively occurred in $52.2 \%$ and in $52.6 \%$ of the cases (9). Interestingly, these indices are significaly elevated in elderly onset PsA, probably reflecting more increased levels of proinflammatory cytokines in comparison with younger onset PsA and a more severe outcome (10-12).

A frequently neglected aspect, which however could be useful in suggesting the diagnosis, is the abundance of the synovial fluid (SF) effusion in patients with PsA, much higher in comparison with other arthropathies (13). These levels reflect the high degree of vascularisation of synovial membrane in PsA, higher than in RA $(14,15)$ and the overexpression of angiogenic factors, such as transforming growth factor $\beta$ (TGF $\beta$ ) and vascular endothelial growth factor (VEGF), were found increased in the SF of PsA (16). When available, SF analysis may offer additive information useful for the diagnosis, such as the increasing number of leukocytes, which underlines the inflammatory nature of the effusion even in a patient with normal serum levels of acute phase response.

\section{DISEASE ACTIVITY}

In PsA, when the most popular laboratory markers of inflammation, such as ESR and CRP, are within normal levels, there is no convincing alternative for the evaluation of disease activity. However, when these two markers are increased, their utility is undeniable. In particular, ESR seems the most related with clinical scores (17). However, it is important to observe that although ESR and/or CRP are included in the most utilised response criteria for RA, such as ACR and DAS, these are also considered reliable in the assessment of PsA (8).

\section{PROGNOSIS}

This is probably the field in which laboratory markers, including ESR and CRP, seem the most useful in PsA. Elevated levels of ESR have been proposed as one of the best predictors of damage progression (18). Gladman et al reported that a low ESR is protective, while an ESR $>15 \mathrm{~mm} / \mathrm{h}$ is one of the factors associated with an increased mortality in PsA $(19,20)$. Interestingly, we found that elevated IL- $1 \beta$ levels in SF of patients with early disease ( $<6$ months), may be predictive of an evolution in polyarticular form at follow-up (21). This observation is in keeping with the crucial role that inflammatory cytokines play in PsA (22), probably related with genetic predisposition. TNF$\alpha$ promoter polymorphism or a gene in linkage disequilibrium with TNF- $\alpha$ may also contribute to confer predisposition or increase susceptibility to psoriasis and PsA (23). One study looking at the TNF $\beta+252$ and TNF $\alpha-308$ polymorphisms did not find any differences in allele frequencies between 
PsA patients and matched controls, however both polymorphisms were significantly associated with the presence of joint erosions and the progression of joint erosions in early PsA (24).

The genetic predisposition has been also investigated by HLA typing. The most involved allele for psoriasis is HLA-CW6, which is also recently known as PSORSI, especially in addition to alleles in linkage disequilibrium HLA B13 and B17 (B57) and the class II allele, HLA DR7 (25-28). The presence of HLA-CW*0602 is associated with more severe and early onset psoriasis (29) and was found in $100 \%$ of patients with guttate psoriasis (30). In PsA, the most frequent associations are HLA-B38 and HLA-B39, both splits of HLA-B16, in peripheral disease and HLA-B27 in axial disease $(27,28)$. Some propose that HLA-DR7 is associated with a more severe outcome and HLADR4 to more frequent erosions, but these data need confirmation (31).

\section{EVALUATION OF DRUG THERAPY}

Laboratory investigations are among the most useful tools to control the influence of drugs, both therapeutic and side effects. Obviously, in the patients having basal high values of ESR and CRP, their reduction was generally interpreted as satisfactory because they were usually associated with the improvement of other response criteria of disease activity. The recent introduction in PsA of anti-TNF- $\alpha$ agents, soon after their demonstration of remarkable efficacy in treating DMARDrefractory RA, has stimulated the research also in the field of the possible laboratory markers. To this purpose several substances have been proposed, but without a definite demonstration of their utility.

TNF- $\alpha$ blockers have demonstrated to be useful in the management of many clinical disease expressions including peripheral arthropathy, axial involvement, enthesopathy and skin manifestations $(32,33)$. Furthermore, they are able to slow down the disease progression, as proven radiologically. Recommendations or guidelines for the anti-TNF use in PsA, carefully consider the heterogeneity of clinical presentations and include ESR and CRP as a marker of disease activity $(34,35)$. However, the observation found in ankylosing spondylitis does not seem to be confirmed in PsA, that patients with elevated CRP or ESR tend to respond better to TNF inhibitor therapy (36).

\section{REFERENCES}

1. Moll JMN, Wright V. Psoriatic arthritis. Semin Arthritis Rheum 1973; 3: 51-78.

2. Berthelot JM. Psoriatic arthritis as a mountain. Reumatismo 2003; 55: 6-15.

3. Punzi L, Podswiadek M, Oliviero F, Sfriso P, Fiocco U, Todesco S. Pathogenetic and clinical rationale for anti-TNF blocking in psoriatic arthritis. Autoimmunity Review, in press.

4. Gladmann D, Shuckett R, Russell ML, Thorne JC, Schachter RK. Psoriatic arthritis: clinical and laboratory analysis of 220 patients. Q J Med 1987; 62: 127-41.

5. Mease P, Goffe BS. Diagnosis and treatment of psoriatic arthritis. Am Acad Dermatol 2004; 52: 1-19.

6. Helliwell PS, Porter G, Taylor WJ. Polyarticular psoriatic arthritis is more like oligoarticular psoriatic arthritis, than rheumatoid arthritis. Ann Rheum Dis, 2007; 66: 113-7.

7. Bogliolo L, Alpini C, Caporali R, Sciré CA, Moratti R, Montecucco CM. Antibodies to cyclic citrullinated peptides in psoriatic arthritis. J Rheumatol 2005; 32: 511-5.

8. Gladman DD, Helliwell P, Mease PJ, Nash P, Ritchlin C, Taylor W. Assessment of patients with psoriatic arthritis. A review of currently available measures. Arthritis Rheum 2004; 50: 24-35.

9. Cervini C, Leardini G, Mathieu A, Punzi L, Scarpa R. Psoriatic arthritis: epidemiological and clinical aspects in a cohort of 1.306 italian patients. Reumatismo 2005; 57: 283-90.

10. Punzi L, Pianon M, Rossini P, Schiavon F, Gambari PF. Clinical and laboratory manifestations of elderly onset psoriatic arthritis: a comparison with younger onset disease. Ann Rheum Dis 1999; 58: 226-9.

11. Punzi L, Pianon M, Gambari PF. Normal values of laboratory tests in elderly onset psoriatic arthritis. Ann Rheum Dis 2000; 59: 239-40.

12. Kane D, Stafford L, Bresnihan B, FitzGerald O. A prospective, clinical and radiological study of early psoriatic arthritis: an early synovitis clinic experience. Rheumatology (Oxford) 2003; 42: 1460-8.

13. Punzi L, Bertazzolo N, Pianon M, Michelotto M, Cesaro G, Gambari PF. The volume of synovial fluid effusion in psoriatic arthritis. Clin Exp Rheumatol. 1995; 13: 535-6.

14. Veale D, Yanni G, Rogers S, Barnes L, Bresnihan B, Fitzgerald O. Reduced synovial membrane macrophage numbers, ELAM-1 expression, and lining layer hyperplasia in psoriatic arthritis as compared with rheumatoid arthritis. Arthritis Rheum. 1993; 36: 893-900.

15. Fiocco U, Cozzi L, Chieco-Bianchi F, Rigon C, Vezzu M, Favero E, et al. Vascular changes in psoriatic knee joint synovitis. J Rheumatol 2001; 28: 2480-6.

16. Fearon U, Reece R, Smith J, Emery P, Veale DJ. Synovial cytokine and growth factor regulation of MMPs/TIMPs: implications for erosions and angiogenesis in early rheumatoid and psoriatic arthritis patients. Ann N Y Acad Sci 1999; 878: 619-21.

17. Kane DJ, Saxne T, Doran JP, Bresnihan B, FitzGerald O. A comparison of the ESR, CRP, serum amyloid A 
and cartilage oligomeric matrix protein in assessing inflammation and predicting radiological outcome in eraly psoriatic arthritis. Arthritis rheum 2003; 48 (suppl 9): s178 (Abstract).

18. Pipitone N, Kingsley GH, Manzo A, Scott DL, Pitzalis C. Current concepts and new developments in the treatment of psoriatic arthritis. Rheumatology (Oxford). 2003; 42: 1138-48.

19. Gladman DD, Farewell VT. Progression in psoriatic arthritis: role of time varying clinical indicators. J Rheumatol 1999; 26: 2409-13.

20. Gladman DD, Farewell VT, Wong K, Husted J. Mortality studies in psoriatic arthritis: results from a single outpatient center. II.Prognostic indiators of death. Arthritis Rheum 1998; 41: 1103-10.

21. Punzi L, Bertazzolo N, Pianon M, Rizzi E, Rossini P, Gambari PF. Value of synovial fluid interleukin-1 beta determination in predicting the outcome of psoriatic arthritis. Ann Rheum Dis 1996; 55: 642-4

22. Ritchlin C, Haas-Smith SA, Hicks D, Cappuccio J, Osterland CK, Looney RJ. Patterns of cytokine production in psoriatic synovium. J Rheumatol 1998; 25: 1544-52.

23. Hohler T, Kruger A, Schneider PM, Schopf RE, Knop J, Rittner C, et al. A TNF- $\alpha$ promoter polymorphism is associated with juvenile onset psoriasis and psoriatic arthritis. J Invest Dermatol 1997; 109: 562-5.

24. Balding J, Kane D, Lingstone W, Mynett-Johnson L, Bresnihan B, Smith O, et al. Cytokine Gene Polymorphisms: Associations with Psoriatic Arthritis Susceptibility and Severity. Arthritis Rheum 2003;48:1408-13

25. Henseler T. The genetic of psoriasis. J Am Acad Dermatol 1997; 37: S1-11.

26. Gladman DD, Cheung C, Ng CM, Wade JA. HLA-C locus alleles in patients with psoriatic arthritis. Hum Immunol 1999; 60: 259-61.

27. Hohler T, Marker-Hermann E. Psoriatic arthritis: clinical aspects, genetics, and the role of T cells. Curr Opin Rheumatol 2001; 13: 273-9.
28. Rahman P, Elder JT. Genetic epidemiology of psoriasis and psoriatic arthritis. Ann Rheum Dis 2005; 64 (suppl II): ii37-ii39.

29. Gudjonsson JE, Karason A, Antonsdottir AA, Runarsdottir EH, Gulcher JR, Stefansson K, et al. HLA-CW6positive and HLA-CW6-negative patients with psoriasis vulgaris have distinct clinical features. J Invest Dermatol 2002; 118: 362-5.

30. Mallon E, Bunce M, Savoie H, Rowe A, Newson R, Gotch F, et al. HLA-C and guttate psoriasis. Br J Dermatol 2000; 143: 1177-82.

31. Gladman DD, Farewell VT, Rahman P, Schentag CT, Pellett F, Ng CM, Wade JA. HLA-DRB1*04 alleles in psoriatic arthritis: comparison with rheumatoid arthritis and healthy controls. Hum Immunol. 2001; 62: 1239-44.

32. Mease PJ, Goffe BS, Metz J, VanderStoep A, Finck B, Burge DJ. Etanercept in the treatment of psoriatic arthritis and psoriasis: a randomised trial. Lancet 2000; 356: 385-90

33. Brandt J, Braun J. Anti-TNF-alpha agents in the treatment of psoriatic arthritis. Expert Opin Biol Ther 2006; 6: 99-107.

34. Salvarani C, Olivieri I, Cantini F, Marchesoni A, Punzi L, Scarpa R, et al. Recommendations for the appropriate use of anti-TNFalpha therapy in patients with psoriatic arthritis of Italian Rheumatology Society. Reumatismo 2004; 56: 136-8.

35. Pham T, Guillemin F, Claudepierre P, Luc M, MiceliRichard C, Fautrel B, et al. TNF antagonist therapy in ankylosing spondylitis and psoriatic arthritis: recommendations of the French Society of Rheumatology. Joint Bone Spine 2006; 73: 547-53.

36. Braun J, Brandt J, Listing J, Zink A, Alten R, Burmester $\mathrm{G}$, et al. Long-term efficacy and safety of infliximab in the treatment of ankylosing spondylitis: an open, observational, extension study of a three month, randomised, placebo-controlled trial. Arthritis Rheum 2003; 48: 2224-33. 